\title{
Supervisão colaborativa e desenvolvimento profissional em Enfermagem
}

\author{
Collaborative supervision and professional development in Nursing \\ Supervisión colaborativa y desarrollo profesional en Enfermería
}

Germana Manuela da Silva Pinheiro*; Ana Paula Morais de Carvalho Macedo**; Nilza Maria Vilhena Nunes da Costa***

\section{Resumo}

Enquadramento: A supervisão colaborativa fundamenta a permanente transformação das práticas profissionais, numa perspetiva coformativa e desenvolvimentista.

Objetivo: Este estudo visa compreender as conceções dos enfermeiros sobre a supervisão colaborativa e o desenvolvimento profissional na prática de cuidados.

Metodologia: Estudo empírico qualitativo, este estudo de caso integra a equipa de Enfermagem de um serviço de Medicina Interna num Centro Hospitalar da região Norte de Portugal $(\mathrm{N}=29)$. Os dados foram obtidos através de análise documental, observação não participante e entrevista semiestruturada.

Resultados: Os participantes consideram que colaborar é partilhar, trabalhar em equipa e ajudar o outro, existindo privilegiados momentos colaborativos na prática de cuidados. A supervisão surge como uma realidade ainda distanciada da prática e os enfermeiros tendem a uma visão verticalizada do processo supervisivo. Como contributos para o desenvolvimento profissional, os enfermeiros salientam a formação contínua, a colaboração e a inter-relação da pessoa, do meio e dos outros.

Conclusão: Apesar da espontaneidade e informalidade da supervisão e da colaboração, estas práticas encontram-se intimamente relacionadas com o contínuo desenvolvimento profissional em Enfermagem.

Palavras-chave: equipe de enfermagem; comportamento cooperativo; competência profissional.

\begin{abstract}
Background: Collaborative supervision explains the permanent transformation of professional practices from a coformative and developmental perspective.

Objective: This study aims to identify the nurses' conceptions of collaborative supervision and professional development in nursing care practice.

Methodology: A qualitative empirical case study, including the Nursing team of an Internal Medicine unit of a Hospital Centre in Northern Portugal $(\mathrm{N}=29)$. Data were obtained through document analysis, non-participant observation and semi-structured interviews. Results: Participants consider that collaborating means sharing, working in a team and helping the other, and that there are privileged collaborative moments in nursing care practice. Supervision emerges as a reality still apart from practice, and nurses tend to consider the supervisory process from a vertical perspective. As contributions to their professional development, nurses emphasise lifelong training, collaboration and the relationship between the person, the environment and the others.

Conclusion: Despite the spontaneity and informality of both supervision and collaboration, these practices are closely related to the continuing professional development in Nursing.
\end{abstract}

Keywords: nursing, team; cooperative behavior; professional competence.

\footnotetext{
* Mestrado em Supervisão ( $2^{\circ}$ Ciclo). Enfermeira do Centro Hospitalar Tâmega e Sousa, E.P.E., 4590-389, Freamunde, Portugal [germanapinheiro@sapo.pt]. Morad para correspondência: Travessa de Matos, no 67, 4590-389, Freamunde, Portugal.

** Doutoramento em Educação, área de Conhecimento de Organização e Administração Escolar: Professora Coordenadora da Escola Superior de Enfermagem da Universidade do Minho, 4715-327, Braga, Portugaal [amacedo@ese.uminho.pt]. *** Doutoramento em Educação, área da Didática. Investigadora do CIDTFE. Professora Catedrática da Universidade de Aveiro, 3810-193, Aveiro, Portugal [nilzacosta@ua.pt].
}

\section{Resumen}

Marco contextual: La supervisión colaborativa sostiene una transformación permanente de las prácticas profesionales, en una perspectiva co-formativa y de desarrollo.

Objetivo: Este estudio tiene como objetivo comprender las concepciones de los enfermeros acerca de la supervisión colaborativa y el desarrollo profesional en la práctica asistencial. Metodología: El estudio empírico cualitativo, en concreto, un estudio de caso, incluye la participación de un equipo de enfermería de un servicio de medicina interna de un hospital de la región Norte de Portugal $(\mathrm{N}=29)$. Los datos fueron obtenidos a través de un análisis documental, una observación no participante y una entrevista semiestructurada.

Resultados: Los participantes consideran que colaborar es compartir, trabajar en equipo o ayudar a los demás, y que, en la pratíca asistencial existen momentos privilegiados de colaboración. La supervisión emerge como una realidad aún lejana de la práctica y los enfermeros tienden a una visión vertical del proceso de supervisión. Como contribuciones para el desarrollo profesional, los enfermeros enfatizan la formación continua, la colaboración y la interrelación entre la persona, el medio ambiente y los demás.

Conclusión: A pesar de la espontaneidad e informalidad de la supervisión y colaboración, estas prácticas están estrechamente relacionadas con el desarrollo profesional continuo en la enfermería.

Palabras clave: grupo de enfermería; conducta cooperativa; competencia profesional.

Recebido para publicação em: 11.03 .13

Aceite para publicação em: 28.02 .14 


\section{Introdução}

O desenvolvimento profissional contínuo passou a constituir uma meta inquestionável na sociedade atual. Este conceito engloba processos de reflexão, de interação com o meio envolvente e de colaboração, com vista a percursos formativos pertinentes e à permanente renovação pessoal e profissional. Nesta linha de pensamento, a supervisão colaborativa tem por base a interação, a mediação entre supervisor e supervisionado e a partilha de saberes, experiências e objetivos fundamentais no atual contexto da formação contínua em Enfermagem. Todavia, de acordo com a experiência profissional em contexto da prática de cuidados, percebe-se que o trabalho colaborativo desenvolvido pelos enfermeiros encontra barreiras e constrangimentos capazes de pôr em causa a prática de supervisão dentro de uma perspetiva desenvolvimentista. Neste sentido, existem motivos pelos quais se opta por investigar esta temática. Por um lado, a escassez de estudos neste domínio, por outro lado, a possibilidade de compreensão do alcance da supervisão colaborativa no desenvolvimento profissional dos enfermeiros. E, por último, o designado Modelo de Desenvolvimento Profissional, que reconhece a importância da criação de pontes de colaboraçãa entre os enfermeiros, de modo a estimular a (des/re)construção das práticas e o desenvolvimento profissional contínuo (Conselho de Enfermagem, 2010). Neste sentido, para compreender o objeto do estudo em toda a sua complexidade, foi formulado um conjunto de questões, que nortearam o processo investigativo: 1) Quais as conceções dos enfermeiros sobre a relação entre a colaboração e a supervisão na prática de cuidados?; 2) Quais os fatores que, no entender dos enfermeiros, podem facilitar ou dificultar a implementação do trabalho colaborativo na prática de cuidados?; e 3) Quais as conceções dos enfermeiros sobre os contributos das práticas de colaboração no contexto profissional?.

Por conseguinte, o estudo está focalizado nas conceções dos enfermeiros sobre a supervisão colaborativa na prática de cuidados e a sua relação com o desenvolvimento profissional.

\section{Enquadramento}

No contexto profissional atual é fundamental que se abandone o individualismo e se valorize a partilha, o confronto de ideias e a reflexão conjunta. Neste âmbito, referindo-se ao trabalho colaborativo no âmbito da formação contínua, Roldão (2007) menciona que se organiza “... essencialmente como um processo de trabalho articulado e pensado em conjunto, que permite alcançar melhor os resultados visados, com base no enriquecimento trazido pela interacção dinâmica de vários saberes específicos e de vários processos cognitivos ..." (p. 27). Assim, o desenvolvimento profissional é perspetivado de modo contínuo, ancorado na reflexão coletiva sobre a ação, visando a reconceptualização permanente das práticas profissionais.

No âmbito do desenvolvimento profissional em Enfermagem pode-se salientar o contributo de Benner (2001), especificamente em como se processa o desenvolvimento das competências em Enfermagem. Esta autora, tendo por base o modelo de Dreyfus e Dreyfus, de 1980, elucida que o desenvolvimento profissional do enfermeiro se processa progressivamente de iniciado a perito, através da aquisição de novos conhecimentos e competências.

Sendo a Enfermagem uma disciplina que age num meio em constante mutação, a formação contínua é perspetivada como um processo de permanente inacabamento, tendo como objetivo o desenvolvimento pessoal, profissional e do contexto de trabalho (Rocha \& Sá-Chaves, 2012). A formação contínua constitui uma estratégia que fomenta a atualização e expansão dos conhecimentos em Enfermagem e a permanente renovação das práticas profissionais, mediante a análise crítico-reflexiva das situações vivenciadas (Abreu, 2007; Serrano, Costa, \& Costa, 2011). Neste contexto, a reflexão constitui um meio que permite aos enfermeiros (des/re)construir a ação, possibilitando adquirir novos significados e modos renovados de agir. Assim, a experiência em contexto da prática emerge como uma relevante fonte de aprendizagem, na qual ocorrem momentos formativos de eleição. Destes, salientam-se as passagens de turno, as reuniões e a formação em serviço que, apesar de serem momentos formativos que não estão livres de conflitos ou divergências, em virtude da abertura ao diálogo e à reflexão e debate colegiais, constituem espaços privilegiados de formação em contexto de trabalho (Macedo, 2012). Estes espaços de reflexão e partilha consistem em singulares momentos colaborativos que possibilitam 
colocar dúvidas, partilhar saberes e experiências e encarar os problemas da prática sob diversas perspetivas.

O desenvolvimento profissional atual engloba a abertura ao diálogo participativo, ao confronto de ideias, pois é na intersubjetividade que se consegue encontrar a solução considerada mais adequada para um determinado problema. Deste modo, a colaboração proporciona um espaço de reflexão coletiva, onde o diálogo colegial e construtivo permite a renovação das práticas e o desenvolvimento profissional dos enfermeiros. Segundo Hargreaves (1998) a colaboração constitui uma “... estratégia particularmente frutuosa de fomento do desenvolvimento profissional ..." (p. 209).

Neste âmbito, este autor expõe que o ambiente relacional no trabalho colaborativo engloba várias dimensões, designadamente: a confiança entre os diferentes sujeitos, o empenbo mútuo, o empreendimento conjunto e o repertório partilhado. Para além disso, Hanson e Spross (2009), tendo por base a análise de Steele, em 1986, consideram que a colaboração entre os profissionais de saúde encerra algumas caraterísticas, designadamente: confiança e respeito mútuo, compreensão recíproca, maturidade profissional, reconhecimento da mais-valia dos parceiros e disposiçã̃o para negociar. Para estas autoras, a colaboração em Enfermagem exige que se transformem situações potencialmente competitivas em oportunidades para trabalhar coletivamente que possam conduzir a benefícios mútuos.

Referindo-se aos contributos da colaboração, Hargreaves (1998) menciona que possibilita realçar a satisfação pessoal e profissional, a autonomia, a reflexão contextualizada, a eficiência e a eficácia acrescidas e o desenvolvimento profissional contínuo. Neste âmbito, Boavida e Ponte (2002) expõem que, mediante a aprendizagem e a reflexão conjuntas, criam-se as "... condições para enfrentar, com êxito, as incertezas e obstáculos que surgem" (p. 3) nas práticas profissionais. Nesta linha de pensamento, Day (2001) refere que a colaboração diminui o sentimento de impotência dos profissionais e aumenta a autoeficácia individual e coletiva.

Apesar dos contributos inerentes à colaboração no contexto profissional, colocam-se alguns constrangimentos à sua implementação (Hargreaves, 1998). Boavidae Ponte (2002) mencionam, igualmente, certos obstáculos, designadamente: a marcada imprevisibilidade, a dificuldade em "saber gerir a diferença", a necessidade de "saber gerir os custos e os benefícios" e a "tendência" para a "auto-satisfação confortável e complacente" e o "conformismo" (pp. 11-12). Estes obstáculos encerram, eventualmente, o que Hargreaves (1998) denomina de colaboração "confortável e complacente", "conformista", "artificial" e "co-optativa" (pp. 279-280). Hanson e Spross (2009), no âmbito da Enfermagem, identificam também valores, crenças e comportamentos que perpetuam o trabalho individualizado, dificultando o trabalho colaborativo. Entre as várias dificuldades à implementação da colaboração, a falta de tempo e o trabalho acrescido encontram-se entre as mais referenciadas (Heargreaves, 1998; Day, 2001; Hanson \& Spross, 2009; Alarcão \& Roldão, 2010). Apesar das diversas dificuldades à operacionalização da colaboração, a literatura recomenda que mediante o diálogo, a negociação colegial e a resolução conjunta dos problemas, estas poderão ser minimizadas. Assim, a colaboração a longo prazo pode ser tanto gratificante como desafiadora.

Abreu (2007) e Macedo (2012), em conformidade com o referido pelo Conselho de Enfermagem (2010), reconhecem a importância da supervisão ao longo de todo o desenvolvimento profissional do enfermeiro. Nesta linha de pensamento, a ação, a reflexão e a colaboração emergem como alicerces essenciais, pretendendo-se que o supervisor e o supervisionado reflitam conjuntamente sobre os problemas da prática, com vista à "compreensão partilhada dos fenómenos" (Conselho de Enfermagem, 2010, p. 7). Alarcão e Roldão (2010) advogam que a supervisão em contexto profissional necessita passar de uma visão "vertical" para uma "supervisão interpares, colaborativa, horizontal" (p. 19). Com isto, as referidas autoras expõem que a supervisão "ganhou uma dimensão colaborativa, auto-reflexiva e autoformativa ...", à medida que os profissionais adquiriram “... confiança na relevância do seu conhecimento profissional e na capacidade de fazerem ouvir a sua voz como investigadores da sua própria prática e construtores do saber específico inerente à sua função social" (Alarcão \& Roldão, 2010, p. 15). Neste sentido, despontam como essencial a autosupervisão e a heterosupervisão colaborativas, que ao serem vividas num clima de colegialidade democrática possibilitam uma verdadeira (des/re)construção do conhecimento profissional (Alarcão \& Roldão, 2010; Alarcão \& 
Canha, 2013). De acordo com Sullivan e Glanz (2005), é neste contexto que emerge uma supervisão colaborativa e horizontal apoiada em dois princípios fundamentais, nomeadamente: a democraticidade e a liderança com visão. Neste âmbito, o processo supervisivo adquire um caráter dinâmico, onde os diferentes sujeitos podem permutar os papéis que desempenham e o tempo de manutenção, não existindo um supervisor permanente. Segundo esta perspetiva, supervisor e supervisionado assumem uma postura igualitária e democrática, que mediante o feedback bidirecional, a reflexão e a aprendizagem colegiais e compartilhadas, impulsionam a (des/ re)construção das práticas, com vista à autonomia profissional. No âmbito da Enfermagem, Silva, Pires, e Vilela (2011) referem que a supervisão em contexto da prática compreende processos de supervisão interpares, "... emaranhando-se com os processos de certificação, qualidade, segurança dos cuidados e formação em enfermagem" (p. 114).

A supervisão colaborativa na prática de cuidados aproxima-se, deste modo, do processo supervisivo dialógico, igualitário e democrático preconizado por Sullivan e Glanz (2005). É mediante a indagação reflexiva e colegial das práticas, numa interação bidirecional, de co-implicação e de interdependência, que se impulsiona o contínuo desenvolvimento profissional da equipa de Enfermagem e de toda a instituição de saúde.

\section{Metodologia}

O modo como se interpreta a realidade envolvente influencia as opções metodológicas. Neste sentido, o estudo empírico realizado enquadra-se num paradigma interpretativo e numa abordagem qualitativa, pois foca-se essencialmente nos significados que os participantes atribuem às situações vivenciadas. Nas palavras de Yin (2010) o presente estudo enquadra-se num "projecto de caso único integrado" com "unidades múltiplas de análise" (p. 70), porque embora se esteja perante um fenómeno com múltiplas unidades de análise, a colheita de dados, que resulta do estudo empírico, refere-se a um único caso.

Para o desenvolvimento deste artigo, foram utilizadas informações recolhidas durante a realização de um estudo mais alargado (Pinheiro, 2012), desenvolvido em contexto hospitalar, no período de setembro a novembro de 2011, no qual se estudou uma equipa de Enfermagem constituída por 29 enfermeiros de um serviço de Medicina Interna de um Centro Hospitalar da região Norte de Portugal.

Qualquer investigação realizada com seres humanos pressupõe questões éticas essenciais. Neste sentido, para além da autorização formal da organização hospitalar, foi protegida a identidade de todos os participantes, obtido o seu consentimento informado de modo livre e esclarecido, bem como garantida a confidencialidade e autenticidade de todas as informações recolhidas.

Numa primeira fase, foram analisados os documentos referentes à formação em serviço e seis atas das reuniões. Numa fase posterior, foram efetuadas sete observações de passagens de turno, distribuídas pelos turnos da manhã e da tarde, e uma observação direta de uma sessão de formação em serviço, inserida numa reunião. Esporadicamente, ocorreram observações ocasionais ou conversas informais, consideradas fontes de informação adicional. Durante o período das observações foi utilizada uma grelha de observação, constituída por dois comportamentos/ discursos observáveis, designadamente: 1) dinâmica do grupo; e 2) práticas colaborativas entre os enfermeiros. Para uma compreensão mais abrangente do objeto de estudo, para além da análise documental e da observação direta, recorreuse, igualmente, à entrevista semiestruturada. $\mathrm{Na}$ impossibilidade de entrevistar todos os elementos do caso, especificamente os 29 participantes, a escolha das unidades de análise baseou-se numa seleção intencional, que possibilitou a compreensão holística da temática em estudo. Deste modo, os participantes foram selecionados com base na sua voluntariedade e de modo a garantir a diversidade nas descrições e interpretações recolhidas. Para assegurar a variedade das conceções sobre o objeto do estudo, os enfermeiros entrevistados foram escolhidos atendendo ao tempo de experiência profissional, ao tempo de serviço, às funções desempenhadas no serviço e à experiência pessoal em supervisão. Neste seguimento, foram realizadas oito entrevistas semiestruturadas, durante as quais se utilizou um guião de entrevista composto por: 1) caraterização dos entrevistados; 2) conceções dos enfermeiros quanto à formação contínua e ao desenvolvimento profissional; 3) conceções dos enfermeiros quanto à 
supervisão; e 4) conceções dos enfermeiros quanto às práticas colaborativas em contexto profissional.

Após a leitura geral dos documentos consultados, das anotações recolhidas e das transcrições das entrevistas, que constituíram o corpus de análise, implementou-se a técnica de análise de conteúdo, de modo a aceder ao significado da informação recolhida. Foi construído um sistema categorial de modo progressivo (Vala, 1986), durante o qual se recorreu ao software de análise qualitativa WebQDA (Web Qualitative Data Analysis). Seguidamente à análise de conteúdo, as informações recolhidas foram cruzadas, de forma a construir um sentido global sobre as conceções dos enfermeiros quanto à supervisão colaborativa e sua relação com o desenvolvimento profissional.

\section{Resultados e Discussão}

Tendo por base as conceções dos enfermeiros participantes emergiram várias dimensões de análise, que se relacionam com as questões de investigação e os objetivos do estudo, nomeadamente: 1) conceções sobre a colaboração; 2) conceções sobre a supervisão; 3) fatores propiciadores ao trabalho colaborativo na prática de cuidados; 4) fatores constrangedores ao trabalho colaborativo na prática de cuidados; e 5) colaboração e desenvolvimento profissional contínuo (Pinheiro, 2012).

No que se refere à primeira questão de investigação, os testemunhos dos participantes revelam que as conceções de colaborar se aproximam de partilhar, trabalhar em equipa ou ajudar o outro, emergindo no discurso dos enfermeiros um repertório partilhado em torno de colegas ou equipa, quando se referem aos outros ou ao grupo.

$\mathrm{Na}$ prática de cuidados foram observados momentos colaborativos de eleição, especificamente as passagens de turno, as reuniões e a formação em serviço, enquanto espaços promotores de partilha de saberes e experiências, bem como do debate e reflexão colegiais. Nestes espaços colaborativos, o nível de interação existente é elevado, o que na opinião de Serrano et al. (2011) "... apela à reflexão, à transformação e por consequência a um saber agir com pertinência ..." (p. 22). Deste modo, estas interações grupais possuem efeitos desenvolvimentistas fundamentais para a implementação de uma cultura coformativa.
Nesses momentos colaborativos o clima relacional foi, essencialmente, positivo e de abertura ao outro, potenciando a (des/re)construção permanente das práticas. Este clima relacional se aproxima de um "... ambiente relacional positivo, interativo, suscetível de criar uma dinâmica espiralada de aprendizagem e de desenvolvimento ..." (Alarcão \& Canha, 2013, p. 30). Todavia, averiguou-se que esses momentos colaborativos vocacionam-se, fundamentalmente, para a resolução de problemas emergenciais, pelo que tendem a escassear as ocasiões de diálogo crítico-reflexivo ou de confronto de ideias. Assim, estas práticas de colaboração remetem para os conceitos de colegialidade artificial e congenialidade (Hargreaves, 1998), tornando-se limitativas e perdendo o caráter dialógico e reflexivo, fundamental ao crescimento profissional contínuo. Para além disto, ao se restringirem à equipa de Enfermagem, remetem para a conceção de cultura balcanizada preconizada por Hargreaves (1998), pois os enfermeiros tendem a fechar-se a contributos externos ao grupo. Neste seguimento, seria fundamental que os momentos colaborativos se tornassem espaços de reflexão interdisciplinar, de modo a dar-se a transição para a colegialidade e a colaboração interpessoal (Day, 2001). Assim, este trabalho colaborativo tende a afastar-se do "... processo de trabalho articulado e pensado em conjunto, que permite alcançar melhor os resultados visados ..." (Roldão, 2007, p. 27). No entanto, ao ser vivenciado de modo espontâneo e informal na prática de cuidados, proporciona oportunidades naturais de aprendizagem ao longo da vida, potencialmente desenvolvimentistas.

Das conclusões extraídas referentes à primeira questão do estudo ressalta, ainda, a problemática da supervisão das práticas de cuidados. Apesar de a supervisão merecer um interesse cada vez mais efetivo por parte das organizações de saúde (Abreu, 2007) continua a transparecer como prática distanciada dos contextos profissionais. Considera-se que para tal contribui não só as conceções dos participantes sobre supervisionar, que se aproximam de inspecionar ou controlar, o que remete para uma visão verticalizada do processo supervisivo, como a ausência da figura do supervisor em contexto da prática de cuidados. No entanto, alguns enfermeiros reconhecem a orientação no processo supervisivo e associam o supervisor clínico à enfermeira-chefe e aos pares.

Para que o processo de supervisão promova a reflexão, a investigação e a experimentação sobre 
a prática de cuidados, torna-se necessário que se utilize uma diversidade de estratégias supervisivas adaptáveis à finalidade pretendida. Neste contexto, os enfermeiros salientam a formulação de questões, a observação, a reflexão, o feedback e a adequação ao nível de desenvolvimento do supervisionado, que possibilitam equacionar modos alternativos de agir, orientar as práticas e garantir a interação coconstrutiva, que respeite a singularidade de cada indivíduo no processo supervisivo.

Quando inquiridos sobre um bom supervisor, os participantes referiram que "não é só observar, é também questionar. (...) Porque se assim não for, nós nunca vamos (...) aperceber da nossa falta de informação" (enfermeiro A). Assim, o bom supervisor deverá ser aquele que "tenha vontade, dinâmica" (enfermeiro E) e que "promove a autonomia" (enfermeiro G). Neste contexto, um dos enfermeiros refere que um bom supervisor é um referencial. "Porque os enfermeiros trabalham muito de acordo com os seus conhecimentos (...) e falta este referencial à Enfermagem" (enfermeiro E). Todavia, uma das características mais referenciadas refere-se às competências relacionais. Neste sentido, os participantes mencionam que um bom supervisor "é um parceiro" (enfermeiro E), ou seja, deverá "ter atributos em termos de relação interpessoal" (enfermeiro D). Deste modo, observa-se um paralelismo entre a imagem que os entrevistados possuem de um bom enfermeiro supervisor e as características destacadas por Alarcão e Canha (2013). O que se aproxima de uma visão democrática, colaborativa, transformadora e desenvolvimentista da supervisão (Sullivan \& Glanz, 2005; Alarcão \& Roldão, 2010; Macedo, 2012; Alarcão \& Canha, 2013).

Ao longo do percurso investigativo verificou-se que um elevado número de participantes possuem formação em supervisão. No entanto, constatou-se que a formação em supervisão adquiriu caráter de obrigatoriedade para a formação de enfermeiros tutores no âmbito dos ensinos clínicos, pelo que os enfermeiros participantes tendem a atribuir-lhe um valor secundário.

No que se refere ao impacto da supervisão emergem apenas contributos positivos, nomeadamente: gestão de sentimentos, qualidade dos cuidados e desenvolvimento contínuo do supervisor e do supervisionado. Deste modo, a supervisão adquire uma dimensão coformativa e desenvolvimentista (Alarcão \& Roldão, 2010; Macedo, 2012).

Os enfermeiros parecem percecionar a supervisão colaborativa como um "... ideal a ser atingido" (enfermeiro D). Esta perspetiva pode dever-se, não só às dificuldades em construírem uma verdadeira cultura colaborativa, como também à desvalorização da informalidade e da espontaneidade do trabalho colaborativo na prática de cuidados. Contudo, alguns participantes consideram que a supervisão colaborativa é viável e que, quanto aos papéis a assumir, poderiam ser supervisores ou supervisionados. Neste contexto, é de salientar que alguns enfermeiros consideram possível, dependendo do momento e da problemática em reflexão, a rotatividade de papéis entre supervisor e supervisionado, o que constitui uma das condições essenciais à implementação da supervisão colaborativa na prática de cuidados.

Relativamente à segunda questão de investigação, os discursos dos enfermeiros evocam alguns fatores pessoais, interpessoais, organizacionais e de contexto que podem influenciar a implementação de uma verdadeira colaboração entre os enfermeiros. Neste âmbito, emergiram como fatores propiciadores à colaboração: 1) abertura ao outro; 2) confiança mútua; 3) comunicação grupal eficaz; 4) negociação; 5) feedback coconstrutivo; 6) empenho mútuo; e 7) liderança democrática. Alguns destes fatores são referenciados por diversos autores, como condições essenciais ao trabalho colaborativo, nomeadamente: a confiança nas pessoas e processos ou a existência de um empreendimento conjunto entre os profissionais (Hargreaves, 1998); a comunicação eficaz que emerge num clima relacional "positivo e interativo" (Alarcão \& Canha, 2013, p. 30); a negociação (Hanson \& Spross, 2009); ou o apoio e encorajamento efetivos de todo o contexto organizacional.

Todavia, como menciona Hargreaves (1998), a colaboração pode "encerrar grandes perigos" (p. 279). Neste contexto, como fatores constrangedores à colaboração, os enfermeiros salientam: 1) cultura do individualismo; 2) características pessoais limitativas; 3) comunicação grupal ineficaz; 4) avaliação dos pares; 5) marcada imprevisibilidade; 6) hierarquização das relações; 7) colegialidade artificial; 8) limitado tempo disponível;9) instabilidade profissional; e 10) marasmo profissional. Alguns destes fatores constrangedores ao trabalho colaborativo são evidenciados em vários 
estudos, designadamente: o isolamento que conduz a pouco feedback (Hargreaves, 1998); as situações potencialmente competitivas, que necessitam ser convertidas em momentos colaborativos (Hanson \& Spross, 2009); as relações assimétricas, que potenciam ambientes onde uns elementos dão muito e recebem pouco, o que dificulta a implementação de espaços colaborativos (Boavida \& Ponte, 2002); a colegialidade artificial (Hargreaves, 1998); a tendência para a auto-satisfação confortável e complacente e o conformismo (Boavida \& Ponte, 2002); o reduzido tempo disponível e a sobrecarga de trabalho (Heargreaves, 1998; Day, 2001; Hanson \& Spross, 2009; Alarcão \& Roldão, 2010). A este propósito, Boavida e Ponte (2002) referem que, por vezes, as equipas são compostas por diferentes elementos que possuem "... objectivos próprios, prioridades diferentes e entendimentos distintos e, por vezes, contraditórios acerca de muitas coisas" (p. 11). Neste sentido, é muito provável que o processo colaborativo possa culminar em atritos, conflitos ou tensões interpessoais. Porém, evitar confrontos com o outro pode ser contraproducente, pois como expõe Vieira (2010), " . . a diversidade é factor de fragmentação e de coesão no seio das comunidades” (p. 289).

Relativamente à última questão de investigação, verificou-se que o denominado Modelo de Desenvolvimento Profissional (Conselho de Enfermagem, 2010) transparece ainda como uma realidade distante do contexto profissional e que os enfermeiros tendem a não possuir uma conceção construída sobre este modelo.

Quanto às conceções de formação contínua, estas aproximam-se da atualização contínua, de abertura dos horizontes pessoais e resposta às necessidades individuais. Estas conceções de formação contínua assemelham-se ao repertório linguístico mencionado por diversos autores (Benner, 2001; Day, 2001; Alarcão \& Roldão, 2010; Rocha \& Sá-Chaves, 2012), enquanto processo de aprendizagem ao longo da vida. Apesar dos participantes considerarem que, por vezes, a formação contínua não se adequa às suas reais necessidades, continuam a formar-se enquanto processo de permanente inacabamento.

Neste processo de aprendizagem ao longo da vida, os participantes salientam aspetos que congregamse num processo tripolar, que engloba processos autoformação, ecoformação e beteroformação (Pineau, 2002). Na relação consigo próprio, os enfermeiros consideram que as características pessoais, as vivências significativas, o percurso profissional efetuado e a reflexão sobre as práticas, contribuem para que a pessoa se desenvolva permanentemente. Na autoformação, Rocha e SáChaves (2012) evidenciam os princípios da autoimplicação e da aprendizagem ao longo da vida e a profissionalidade crítico-reflexiva, enquanto motores que impulsionam a inovação contínua. Nesta relação consigo próprio, os interdiscursos declaram, ainda, que o desempenho de certos cargos específicos ou o contacto com determinados colegas mais curiosos constituem desafios pessoais, que produzem efeitos positivos do ponto de vista desenvolvimentista.

Na relação com o meio, os enfermeiros expõem que um ambiente em constante mutação oferece uma panóplia de experiências que fomentam a formação experiencial continuada. Este conhecimento tácito resulta da experimentação na prática de cuidados, no sentido da resolução dos problemas in loco, perspetivando uma ação futura com maior performance (Benner, 2001; Abreu, 2007; Serrano et al., 2011).

Neste processo tripolar, há ainda a considerar a heteroformação, na qual os enfermeiros citam que a abertura ao outro permite a descoberta de novos saberes e modos alternativos de cuidar. Nesta relação com os outros, desponta, igualmente, a partilha de saberes e experiências, que permite transcender as dúvidas pessoais e a reflexão, e debate colegiais, que facilitam uma ação futura mais refletida, contextualizada e problematizada sobre as práticas. Deste modo, é realçada a mais-valia do efeito multiplicador do diverso no processo formativo (Rocha \& Sá-Chaves, 2012) e evidenciada a importância da reflexão coletiva, que proporciona a abertura dos horizontes individuais limitativos (Hargreaves, 1998; Day, 2001).

No processo de desenvolvimento profissional, foram também congregadas as potencialidades da colaboração. Neste contexto, os enfermeiros evidenciam: 1) o reforço do espírito de equipa, uma vez que favorece uma visão compartilhada dos problemas e estimula o envolvimento da equipa; 2) a expansão dos conhecimentos, pois o encontro com o outro permite o alargamento dos horizontes pessoais limitativos; 3) a reformulação das práticas, porque o trabalho colaborativo facilita a abertura às contribuições e críticas do outro, fundamentais à 
(des/re)construção permanente das práticas; e 4) a melhoria dos cuidados prestados, na medida em que a renovação do conhecimento profissional conduz à melhoria da prática de cuidados. Vários estudos revelaram resultados semelhantes, pois concluíram que os ambientes colaborativos consistem em espaços partilhados de construção de conhecimento (Hargreaves, 1998; Day, 2001; Alarcão \& Roldão, 2010; Alarcão \& Canha, 2013). A partilha com o outro parece promover a segurança dos cuidados e a tomada de decisão mais situada, facilitando a reformulação constante das práticas profissionais. Assim, e de acordo com Alarcão e Canha (2013), a “... supervisão integradora de princípios colaborativos" (p. 63) promove o desenvolvimento profissional de toda a organização.

\section{Conclusáo}

Concluiu-se que as conceções de colaboração aproximam-se de partilhar, trabalhar em equipa ou ajudar o outro, emergindo momentos colaborativos privilegiados, especificamente as passagens de turno, as reuniões e a formação em serviço.

Relativamente à supervisão em contexto da prática, os enfermeiros mencionam que é inexistente o papel do enfermeiro supervisor e tendem a possuir uma visão verticalizada do processo supervisivo. Quanto ao impacto da supervisão, emergem apenas contributos positivos, designadamente a gestão de sentimentos, a qualidade dos cuidados e o desenvolvimento contínuo do supervisor e do supervisionado. No entanto, a supervisão colaborativa continua a ser percecionada como um ideal, dada a dificuldade em se estabelecer uma verdadeira cultura de colaboração. Assim, a colaboração e a supervisão constituem práticas intimamente relacionadas com o desenvolvimento profissional em Enfermagem. Apesar de tenderem a emergir de modo espontâneo e informal na prática de cuidados, o que poderá comprometer o seu caráter formativo e desenvolvimentista, considera-se que fomentam processos de auto e heteroformação, com vista ao desenvolvimento profissional mútuo e contínuo.

Dos interdiscursos emergiram um conjunto de fatores propiciadores e constrangedores ao trabalho colaborativo, importante a ter em consideração na promoção de culturas colaborativas.
$\mathrm{Na}$ problemática do desenvolvimento profissional despontam as potencialidades da colaboração, nomeadamente o reforço do espírito de equipa, a expansão dos conhecimentos, a reformulação das práticas e a melhoria dos cuidados prestados. No processo de desenvolvimento profissional verifica-se que se entrecruzam três dimensões, designadamente a pessoa, o meio e os outros. Para além disso, emerge a questão da formação contínua, enquanto processo de permanente inacabamento.

Este estudo contribuiu para aprofundar os conhecimentos relativos às conceções dos enfermeiros sobre a supervisão colaborativa e a sua relação com o desenvolvimento profissional. Algumas implicações para a prática, como para futuras investigações, surgem realçadas: 1) o atual sistema de avaliação de desempenho valoriza essencialmente o mérito individual, o que poderá potenciar a competitividade entre os enfermeiros, comprometendo o trabalho colaborativo; 2) a questão da formação disponibilizada pelos centros de formação, que ao não atenderem às reais necessidades dos enfermeiros, negligenciam um exercício profissional de qualidade; e 3) a falta de comunicação existente dentro das organizações de saúde. Em analogia com as palavras de Alarcão e Roldão (2010), verifica-se que cada equipa de Enfermagem constitui uma ilha, pelo que se considera essencial que se estabeleçam mais pontes de comunicação entre os diferentes profissionais, potenciadoras de contextos mais colaborativos e pedagógicos.

Perante a instabilidade profissional atual e as contingências economicistas no setor da saúde, o contexto contemporâneo é especialmente constrangedor, pelo que são necessários esforços conjugados para que a supervisão colaborativa possa constituir uma realidade na prática de cuidados. Neste âmbito, para além do apoio efetivo da organização de saúde, torna-se fundamental a emergência de enfermeiros supervisores, que constituam líderes de equipas em aprendizagem e de organizações qualificantes. Finalmente, sugerese o desenvolvimento de projetos colaborativos na prática de cuidados, que congreguem as perspetivas e os objetivos de diferentes enfermeiros, com vista ao desenvolvimento profissional coletivo. Também de interesse é a concretização de estudos nas comunidades de enfermeiros existentes em ambientes virtuais, tendo em vista analisar o seu contributo para o desenvolvimento profissional em Enfermagem, e de 
estudos relacionados com práticas reconhecidas pelo trabalho colaborativo, de modo a compreender como se afigura a coformação em contextos coletivos.

Este trabalho é financiado pela FCT/MEC através de fundos nacionais (PIDDAC) e cofinanciado pelo FEDER através do COMPETE - Programa Operacional Fatores de Competitividade no âmbito do projeto PEst-C/CED/UI0194/2013.

\section{Referências bibliográficas}

Abreu, W. (2007). Formação e aprendizagem em contexto clínico: Fundamentos, teorias e considerações didácticas. Coimbra, Portugal: Formasau.

Alarcão, I., \& Canha, B. (2013). Supervisão e colaboração: Uma relação para o desenvolvimento. Porto, Portugal: Porto Editora.

Alarcão, I., \& Roldão, M. (2010). Supervisão. Um contexto de desenvolvimento profissional dos professores ( $2^{\mathrm{a}}$ ed.). Mangualde, Portugal: Edições Pedago.

Benner, P. (2001). De iniciado a perito: Excelência e poder na prática clínica de enfermagem (ed. comemorativa). (A. Queirós \& B. Lourenço, Trad.). Coimbra, Portugal: Quarteto. (Obra original publicada em 1984).

Boavida, A., \& Ponte, J. (2002). Investigação colaborativa: Potencialidades e problemas. In Grupo de Trabalho sobre Investigação (Ed.), Reflectir e investigar sobre a prática profissional (pp. 1-15). Lisboa, Portugal: APM.

Conselho de Enfermagem. (2010). Modelo de desenvolvimento profissional: Fundamentos, processos e instrumentos para a operacionalização do sistema de certificação de competências. Lisboa, Portugal: Ordem dos Enfermeiros.

Day, C. (2001). Desenvolvimento profissional de professores: Os desafios da aprendizagem permanente. Porto, Portugal: Porto Editora.

Hanson, C., \& Spross, J. (2009). Collaboration. In A. Hamric, J. Spross \& C. Hanson (Eds.), Advance practice nursing: An integrate approach (5th ed., pp. 283-314). St. Louis, MO: Saunders Elsevier.
Hargreaves, A. (1998). Os professores em tempos de mudança: O trabalho e a cultura dos professores na Idade Pós-Moderna. Lisboa, Portugal: McGraw-Hill. (Obra original publicada em 1994).

Macedo, A. (2012). Supervisão em enfermagem: Construir as interfaces entre a escola e o bospital. Santo Tirso, Portugal: De facto Editores.

Pineau, G. (2002). Autoformation et approche ternaire: Communication pour le Symposium GRAF de Bordeaux. Retirado de http://llearning.free-h.net/AGRAF/Symposia/ textes/2002/PineauBdx.htm

Pinheiro, G. (2012). Supervisão colaborativa e desenvolvimento profissional em enfermagem (Dissertação de Mestrado). Universidade de Aveiro, Portugal.

Rocha, J., \& Sá-Chaves, I. (2012). Entrevista a especialistas na área científica da supervisão: Professora Idália Sá-Chaves. Indagatio Didáctica, 2(4), 4-39. Retirado de http://revistas. ua.pt/index.php/ID/article/view/1387

Roldão, M. (2007). Colaborar é preciso. Questões de qualidade e eficácia no trabalho dos professores. Noesis, 71, 24-29.

Serrano, M., Costa, A., \& Costa, N. (2011). Cuidar em enfermagem: Como desenvolver a(s) competência(s). Revista de Enfermagem Referência, 3(3), 15-23.

Silva, R., Pires, R., \& Vilela, C. (2011). Supervisão de estudantes de enfermagem em ensino clínico: Revisão sistemática da literatura. Revista de Enfermagem Referência, 3(3), 113-122.

Sullivan, S., \& Glanz, J. (2005). Supervision that improves teaching: Strategies and techniques. Recuperado de http:// www.amazon.com/Supervision-That-Improves-TeachingStrategies/dp/0761939695\#_reader_0761939695

Vala, J. (1986). A análise de conteúdo. In A. Silva \& J. Pinto (Eds.), Metodologia das ciências sociais ( $9^{a}$ ed., pp. 507-535). Porto, Portugal: Afrontamento.

Vieira, F. (2010). Olhares sobre o projecto "línguas e educação: Construir e partilhar a formação" - a paixão na linguagem e a condição da diversidade. In A. Andrade \& A. Pinho (Eds.), Linguas e educação: Práticas e percursos de trabalbo colaborativo. Perspectivas a partir de um projecto (pp. 283294). Aveiro, Portugal: Universidade de Aveiro.

Yin, R. (2010). Estudo de caso: Planejamento e métodos (4ª ed.). (A. Thorell, Trad.). Porto Alegre, Brasil: Bookman. (Obra original publicada em 1984). 
